\title{
PERCEPÇÕES DA SEXUALIDADE DO DOENTE MENTAL PELO ENFERMEIRO ${ }^{1}$
}

Francisco Arnoldo Nunes de Miranda ${ }^{2}$ Antonia Regina Ferreira Furegato ${ }^{3}$

Miranda FAN, Furegato ARF. Percepções da sexualidade do doente mental pelo enfermeiro. Rev Latino-am Enfermagem 2002 março-abril; 10(2):207-13.

Esta pesquisa teve por objetivo identificar as Representações Sociais dos profissionais enfermeiros, expressas nas situações em que a sexualidade do doente mental constitui um fato evidente, nas instituições psiquiátricas. O recurso técnico-metodológico para coleta dos dados, baseado nos procedimentos projetivos, foi denominado Técnica de Investigação em Situações Cotidianas - TSC. Esse instrumento foi composto por dezesseis pranchas com reproduções gráficas da atuação cotidiana desse profissional, das quais foram utilizadas seis, para a análise da sexualidade do doente mental. Dezessete enfermeiros que trabalham em hospitais psiquiátricos de Ribeirão Preto compuseram a amostra. Sua manifestação discursiva mostrou a negação da sexualidade do doente mental, circunscrevendo-a no rol dos desvios, transgressões e doença. Ao negar, adotam uma posição de afastamento, em atitude ora repressiva, ora defensiva. Tal posicionamento revela a estratégia adotada sobre esse saber e poder, cumprindo as determinações do seu estatuto profissional, ir ao encontro às expectativas institucionais e sociais.

DESCRITORES: enfermagem psiquiátrica, sexualidade

\section{PERCEPTIONS OF THE MENTALLY-ILL PERSON'S SEXUALITY BY NURSES}

This research aimed at identifying the social representations of nursing professionals expressed in situations in which the sexuality of mentally-ill people constitutes a visible fact in psychiatric institutions. The technical and methodological resource for data collection, based on projective procedures, was denominated Investigation Technique in Daily Situations - ITDS. This instrument consisted of sixteen boards with graphic reproductions of these professionals' daily actions, from which six were selected for the analysis of the mentally-ill person's sexuality. Seventeen nurses working in psychiatric hospitals in Ribeirão Preto composed the sample. Their discoursive manifestation showed their denials of the mentally-ill person's sexuality, which restrained it as a deviation, misbehavior and disease. By doing so, they take a distant position with repressive or defensive attitudes. This position reveals the strategy adopted in relation to such knowledge and power, following the determinations of their professional code by meeting institutional and social expectations.

DESCRIPTORS: psychiatric nursing, sexuality

\section{PERCEPCIONES DE LOS ENFERMEROS A RESPECTO DE LA SEXUALIDAD DE LOS PACIENTES CON ENFERMEDAD MENTAL}

Este estudio tuvo como objetivo identificar las representaciones sociales de los profesionales de enfermería, evidentes en las situaciones en que la sexualidad del paciente con enfermedad mental es un hecho evidente en las instituciones psiquiátricas. El recurso técnico-metodológico para la recolección de datos basado en los procedimientos proyectivos, fue denominado Técnica de Investigación en Situaciones Cotidianas. (TSC). Este instrumento fue compuesto por dieciséis planchas con reproducciones gráficas de la actuación cotidiana de este profesional, de los cuales fueron utilizadas seis para el análisis de la sexualidad del enfermo mental. Diecisiete enfermeros que trabajan en hospitales psiquiátricos de Ribeirão Preto hicieron parte de la muestra. Los discursos de los enfermeros mostraron la negación de la sexualidad del enfermo mental, tratándolas como desvíos, transgresiones y enfermedad. Al negarlo, los enfermeros adoptan una posición de distanciamiento, con actitudes algunas veces represivas y en otras defensivas. Tal posicionamiento revela la estrategia adoptada sobre ese saber y poder, cumpliendo las determinaciones de su estatuto profesional, ir al encuentro de las expectativas institucionales y sociales.

DESCRIPTORES: enfermería psiquiátrica, sexualidad

\footnotetext{
"Este texto é parte da dissertação de mestrado "Doente mental sexualidade negada"; ${ }^{2}$ Professor Assistente do Departamento de Enfermagem da UNOPAR;

${ }^{3}$ Professor Titular da Escola de Enfermagem de Ribeirão Preto da Universidade de São Paulo, Centro Colaborador da OMS para o desenvolvimento da pesquisa em enfermagem, e-mail: furegato@eerp.usp.br
} 
INTRODUÇÃO

Oexercício da enfermagem está inserido num contexto abrangente. $\mathrm{O}$ caráter dessa profissão, às vezes convergente, múltiplo, heterogêneo, conflitivo, ambivalente, afetivo e valorativo, projeta uma infinidade de questionamentos. Essa situação reflete sua singularidade e a preocupação dos seus atores que buscam conhecimentos sobre a profissão, nos diversos níveis de sua atuação social.

Enquanto elemento catalisador do atendimento ao doente mental, o enfermeiro é o profissional que detém melhor conhecimento da estrutura e da dinâmica do serviço, nas suas 24 horas. Conhece as múltiplas facetas da realidade institucional. Entretanto, 0 enfermeiro, não sabendo como utilizar produtivamente esse conhecimento, enfrenta situações de desgaste físico e emocional.

Lidar com a sexualidade faz parte das atividades que, embora não explicitadas oficialmente, permeiam todas as ações e comportamentos desse profissional, enquanto exigência para desempenhar seu papel e ser socialmente aceito.

A Teoria das Representações Sociais (TRS) oferece um modo particular de observação do fato, do fenômeno, da pessoa ou do assunto. Enquanto dimensão e estratégia metodológica, permite reflexões críticas sobre o espaço dos sujeitos, sua inserção e prática social, conferindo valor ao saber do senso comum e da ciência. Permite enxergar os mecanismos que levam os envolvidos a buscarem o equilíbrio para adaptarem-se, mediante processos compartilhados, nas suas relações intrapessoais, interpessoais e interinstitucionais.

As representações sociais são formas de conhecimento socialmente elaboradas, que contribuem para a compreensão da realidade comum, facilitando a comunicação entre seus membros. São compreendidas a partir do seu contexto de produção.

Pretendendo responder a alguns dos questionamentos sobre 0 exercício da enfermagem psiquiátrica no seu cotidiano, estamos desenvolvendo um projeto de pesquisas sobre esta profissão, dentre as quais a presente investigação teve por OBJETIVO identificar as Representações Sociais dos enfermeiros, expressas através da sua percepção da sexualidade do doente mental.

\section{CONSTRUÇÃO DA INVESTIGAÇÃO}

A fundamentação projetiva

O recurso técnico-metodológico foi baseado nos métodos projetivos. Alguns procedimentos projetivos inspiram-se em recursos gráficos, referentes a uma problemática peculiar. A vantagem decorre da possibilidade de sua utilização e aplicação, facultando a articulação entre desenho, atividade e linguagem. 0 desenho constitui, por si mesmo, uma manifestação discursiva e, por conseguinte, assume uma forma comunicativa. A interação entre pesquisador e pesquisado assume 0 aspecto de transicionalidade ${ }^{(1)}$.

As regras desse "brincar", enquanto investigação, assumem peculiaridades específicas para cada um dos envolvidos: o sujeito sabe que está sendo investigado, embora desconheça as regras do jogo; o pesquisador sugere a "brincadeira" com algum tipo de técnica projetiva, buscando uma resposta, feita de modo cifrado ${ }^{(2)}$.

Os procedimentos projetivos possibilitam questionamentos da ação, da decisão e da reação descontextualizadas. Favorece uma investigação ao nível inconsciente e, devido à diminuição das atitudes defensivas, evita respostas racionais e socialmente corretas. Uma das contribuições desse procedimento é o teste de complemento de diálogos (Teste de Rosenzweig), associando-se imagens às frases ${ }^{(3)}$.

Com base nestes argumentos, adotou-se a técnica projetiva para investigar situações do cotidiano institucional onde atua 0 enfermeiro.

A construção gráfica do instrumento

$O$ instrumento do presente estudo foi denominado de Técnica de Investigação em Situações Cotidianas - TSC.

A cartilha com o título "O dia-dia do profissional enfermeiro", composta de 16 pranchas (Tabela 1), contém cenas de situações vividas, imaginadas e/ou relatadas, no decurso de uma jornada de trabalho do enfermeiro ${ }^{(4)}$.

Cada página da cartilha mostra uma cena, contendo, explicitamente ou não, um diálogo entre os personagens envolvidos, apresentando imagens capazes de evocar os significados. Os temas são elencados seqüencialmente, tal como uma rotina institucional, independentemente do período da jornada de trabalho do profissional enfermeiro:

Tabela 1 - Temas da Cartilha do T.S.C.

\begin{tabular}{|c|c|}
\hline 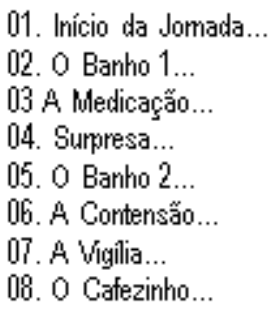 & $\begin{array}{l}\text { 09. A Dança... } \\
\text { 10. O Olhar... } \\
\text { 11. O Banho } 3 \ldots \\
\text { 12. O Grupo... } \\
\text { 13. A Fuga... } \\
\text { 14. O Relato das Ocorências... } \\
\text { 15. A Saída... } \\
\text { 16. Descanso... }\end{array}$ \\
\hline
\end{tabular}

O percurso da coleta de dados

A coleta dos dados foi realizada nas 5 instituições públicas que prestavam assistência ao doente mental, no município de Ribeirão Preto, totalizando 17 enfermeiros entrevistados: 08 do Hospital 
Psiquiátrico de Ribeirão Preto, 4 da Unidade de Internação do Hospital das Clínicas da FMRP, 2 do Sanatório Espírita Vicente de Paulo, 1 da Unidade de Emergência do HC/FMRP e 2 do Hospital-Dia do HC/ FMRP.

O sujeito expressou-se, complementando o diálogo sugerido no desenho de cada prancha do TSC, registrando o que falaria e o que imaginaria na circunstância da cena.

As respostas foram registradas, manuscritas na própria cartilha ou gravadas em fita cassete. As observações do pesquisador foram registradas no Diário de campo.

Todos os 17 participantes, após esclarecidos, concordaram livremente em participar da pesquisa, cuja proposta foi aprovada pelo Comitê de Ética e pelas respectivas Instituições onde o trabalho foi realizado.

O procedimento de análise

Das 16 pranchas do TSC, as quais apresentavam cenas do dia-a-dia de trabalho dos enfermeiros, foram selecionadas 6 que focalizavam a sexualidade do doente mental, conforme descrito no Tabela $2^{*}$.

Tabela 2 - Pranchas selecionadas do TSC sobre a sexualidade do doente mental

D.02-0 Banho 1 - Sua temática revela o homossexualismo masculino. Os corpos dos personagens apresentam-se em posiçẫo anterior, priorizando a cabeça e o tronco.

D.04- A Supresa - A temática é centrada na fantasia sexual do doente mental, focalizando a face e sua expressẫo em plano anterior.

D.05- 0 Banho 2 - 0 auto-rotismo[masturbaçẫo masculina] revela-se na temática desta cena. Apresenta a exposiçẫo do corpo masculino em plano posterior.

D.09-A Dança - A interaçẫo física entre o casal focaliza o movimento dos personagens, adequadamente vestidos, em plano anteroposterior.

D.10-0 Olhar- A temática é o homossexualismo feminino, focalizando o othar por meio da face, cuja construçã̃o se apresenta em plano lateral.

D.11- 0 Banho 3 - 0 erotismo representa a mensagem desta cena. A exposiçẫo corporal apresenta-se parcialmente, focalizando o como feminino em plano anterior.

Iniciamos a análise, olhando o material coletado descompromissadamente, cujo conteúdo foi revisto e analisado em 4 etapas (Tabela 3).

Essa sistematização é um artifício para atenuar expectativas pessoais do entrevistador e poder afastar as tentativas de enquadrar o material coletado em determinado foco ${ }^{(2)}$. O olhar repetitivo sobre os dados tem, por finalidade, captar as mensagens contidas nos dados, os elementos discursivos, os elos que emergem das diversas situações e o estabelecimento do vínculo entre o sujeito, o objeto e o contexto. A apreensão prioriza aquilo que se destaca, enquanto elemento significativo que contribui para a compreensão da realidade e seus mecanismos de adaptação. Enquanto estratégia metodológica, a Teoria das Representações Sociais permitiu reflexões críticas sobre a sexualidade do doente mental, segundo a percepção dos enfermeiros.

Tabela 3 - Etapas da observação e análise dos dados do TSC sobre a sexualidade do doente mental

FASE 1 - Leitura flutuante dos dados das 16 pranchas. Interpretaçẫo de cada uma das cenas e seu vínculo com a entrevista;

FASE 2 - Leitura das unidades de entrevistas e respectivas interpretaçốes;

FASE 3 - Leitura flutuante do conjunto das 17 entrevistas. (A delimitaçẫo das 6 pranchas ocomeu nessa etapa, com base no interesse temáticol;

FáSE 4 - Releitura das 6 cenas sobre a sexualidade, selecionadas com suas respectivas unidades de entrevista, totalizando 102 unidades. Feito o recorte dos diálogos, com vistas à apreensấo de unidades de significados, cada unidade foi agrupada na temática comespondente, em 6 categorias. 0 conjunto de falas recortadas e agnupadas sob um eixo comum foi analisado, comparado com as interpretaçôes das unidades de entrevista e com a literatura, identificando as Representaçốes Sociais da sexualidade do doente mental pelos enfermeiros.

\section{APRESENTAÇÃO, ANÁLISE E DISCUSSÃO DOS RESULTADOS}

Do universo investigado, somente 2 enfermeiros são do sexo masculino, enquanto 15 pertencem ao sexo feminino. Doze estavam na faixa dos 30 a 40 anos, e cinco, entre 40 e 50 anos. 0 tempo de serviço na área variou de 5 meses a 20 anos.

O tempo utilizado para se responder à cartilha do TSC variou de 25 minutos a 2 horas e 25 minutos, estando a freqüência média em torno de 50 minutos.

A análise do conteúdo expresso pelos enfermeiros permitiu que se reordesse dessa percepção em 6 categorias, apresentadas com a respectiva discussão dos dados.

No cotidiano do profissional enfermeiro, o discurso

O cotidiano é o mundo da rotina, em que a repetição das atividades do dia-dia permite a recriação permanente da vida social, expressa, na consciência dos indivíduos, como uma consciência

\footnotetext{
* As 10 pranchas excluídas da presente análise, devidamente respondidas pelos 17 enfermeiros dos 5 serviços psiquiátricos de Ribeirão Preto, serão analisados em outro estudo
} 
prática ${ }^{(5)}$. Dessa forma, o cotidiano estimula a capacidade reflexiva dos indivíduos.

A capacidade reflexiva dos indivíduos, engendrada na vida cotidiana, é entendida como aquela que opera, em parte, no nível discursivo de pessoas que sabem o que fazem e por que o fazem.

As manifestações dialógicas, captadas pelo TSC, revelam a natureza dessa dimensão. São entendidas como discursos, considerando-se sua relação objetal imediatizada por meio da relação de troca contínua com o seu contexto, enquanto produtor de elaborações simbólicas. 0 discurso incorpora, na sua definição, as determinações sociais e textuais ${ }^{(5)}$ que, a seu turno, inscrevem-se em sua prática.

O conhecimento sobre determinado assunto pode ser mascarado frente à predisposição do sujeito em atender aos estímulos, uma vez que, diante de certos problemas, todo indivíduo é inculto ${ }^{(6)}$.

Embora todos os entrevistados sejam detentores de formação acadêmica, o enfermeiro torna-se inculto, enquanto estratégia de adequação, para revelar 0 saber e o poder sobre a sexualidade do doente mental.

Ao adotar essa estratégia, cada um utiliza seu modo particular para se posicionar sobre a sexualidade do doente mental e, assim, circunscreve a negação na imprecisão dos sinônimos atribuídos. Lançado no espaço da sua atuação, esse profissional nega, pois, somente dessa forma, consegue compartilhar 0 assunto e indicar o grau de focalização sobre o tema.

A distância e o grau de implicação em relação ao objeto social, variam, necessariamente (...), como tal a interação social (...) implicada ou empenhada na substância e nos efeitos de seus próprios juízos e opiniões ${ }^{(6)}$.

Seu posicionamento, enquanto opinião, revela seu comportamento e seus juízos de valor, direcionando o desempenho desse papel profissional que, à primeira vista, tende a uma certa neutralidade sobre as manifestações da sexualidade do doente mental.

No cotidiano do profissional enfermeiro, o ver

Trata-se do primeiro impacto que a cena determina sobre o profissional; o impacto que retorna para o enfermeiro, que imediatiza sua elaboração simbólica, refletindo no seu posicionamento profissional.

O procedimento de adequação leva o enfermeiro a adotar estratégias de auto-afirmação, evidenciando-se a ambivalência entre o seu pensar e o seu agir.

O profissional é solicitado, continuamente, a emitir opiniões e transmitir informações, no interior da instituição a que pertence. Apresenta-se sempre apto a dar respostas, por meio de um código comumente aceito.
Nesta investigação, o código comum é a negação da sexualidade do doente mental e, por meio da pressão para a inferência, o enfermeiro estabelece uma maneira de inferir sobre a questão.

A compreensão da sexualidade do doente mental distinguese através de dois tipos de negação, uma chamada polêmica, e a outra, descritiva. A negação descritiva descreve um estado de coisas, parafraseado com o auxílio de um enunciado positivo, que serve para falar do mundo; a negação polêmica contesta, opõe-se a uma asserção anterior, sendo um verdadeiro ato de negação, de refutação do enunciado positivo correspondente ${ }^{(7)}$. Os exemplos que se seguem representam esses dois enfoques, respectivamente, Não é preciso dois tomarem banho debaixo do mesmo chuveiro (11.E5). É 'normal' que se pense em sexo (14.E1).

A tendência à homogeneidade, na atitude do enfermeiro, tem por base a forma como a sexualidade é abordada no contexto institucional, sem eliminar a interferência da maneira como cada um vê e interpreta a questão.

Todo indivíduo, na sua vida cotidiana, sofre diversas pressões para assumir posições práticas e normativas sobre os mais diversos assuntos ${ }^{(5)}$. A sexualidade, claramente vislumbrada na concretude do corpo do doente mental, é um objeto de ação do enfermeiro e de pressão social para sua negação.

No caleidoscópio teórico da compreensão psicossocial, a negação da sexualidade do doente mental

O grupo de enfermeiros deste estudo não nega simplesmente esse aspecto da conduta da pessoa. No silêncio das muitas palavras que estruturam o seu discurso, observa-se certa imprecisão informativa. O sentido contido nas dimensões da realidade social, associadas à produção da representação social da sexualidade do doente mental, vista pelos enfermeiros, exigiu uma compreensão dos dados, permitindo destacar o saber sobre o foco dessa investigação. Foi preciso desarticular seus discursos, decompondoos, deixando emergir o sentido contido nas palavras.

Um signo lingüístico é motivado por uma palavra, quando esta evoca as partes que o compõem e outras que the são associadas $^{(6)}$. Todavia, não se sabe o quê e o porquê dessa negação, além das manifestações discursivas manifestas, uma vez que a noção de negação é ambígua ${ }^{(7)}$.

Sobre o corpo, a pressão para o preconceito - a sexualidade como discurso social

O preconceito evidente sobre a sexualidade do doente mental é parte de um mascaramento social ou uma negação maior e 
ilegítima. A negação, reproduzida no contexto institucional e profissional, representa um fragmento da sociedade.

A imagem corporal do doente mental, no contexto institucional, pode ser descrita como um corpo desprovido de beleza e de vigor físico. Sobre os aspectos físicos dessa clientela incide 0 preconceito por não se reconhecer, no contexto institucional, o corpo jovem, ativo, útil e desejado.

Por ocasião dos cuidados da enfermagem ao doente mental, localizados no corpo do paciente, atuam as estruturas fisiológica e libidinal que compõem a imagem corporal e sociológica ${ }^{(8)}$.

0 cuidado de enfermagem, direcionado para 0 aspecto fisiopatológico, no sentido amplo da atuação profissional, está sempre alerta para os perigos dessa estrutura, afastando o profissional, quando confrontado com as zonas erógenas, especialmente a genitália.

Preferencialmente, os cuidados "devem" estar a cargo de profissionais do mesmo sexo, o que não exclui a presença das manifestações libidinais. Essa situação real e presente (não dita e não ensinada) leva o profissional a adotar 0 afastamento e até a negação da mesma.

A fragmentação corporal começa no ensino. É reforçada a estrutura fisiopatológica, com procedimentos técnicos sistematizados, de prevenção, promoção e manutenção da saúde, dentro do modelo organicista. Entretanto, há obscurecimento das outras estruturas que complementam a noção de imagem corporal, como se as mesmas se estruturassem em dimensões diferentes, ou seja, o ensino omite os aspectos libidinal, emocional e sociológico da conduta humana.

Sobre o corpo, a pressão para o estigma - a sexualidade como desvio

O indivíduo é percebido a partir de certos atributos que 0 identificam socialmente. $O$ estigma marca a pessoa, acusa, censura, condena.

O estigma apresenta como característica uma evidência sobre o corpo do outro, que passa a ser considerado diferente, passível de reclassificação, podendo ser visto como um defeito, uma fraqueza ou uma desvantagem.

A negação da sexualidade do doente mental coaduna-se com a noção de desvio, por ser indicativo de estigma, visto que as deformidades físicas e os problemas relacionados ao caráter da pessoa dão sustentação a esse quadro.

A atuação do enfermeiro perante as manifestações da sexualidade do doente mental, colocadas nas pranchas deste estudo, apresenta-se revestida de um papel socialmente aceito, identificado na sua relação institucional, na medida em que sua atitude de concepção controladora da informação e da identidade pessoal do doente mental, é tratada como desvio (Tabela 4).

Tabela 4 - A negação da sexualidade do doente mental

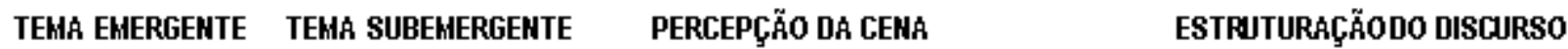

“0 Banho 1...”

Homo ssexualismo

masculino

“A Surpresa...” Fantasia Sexual

"OBanho 2.."

Auto-erotismo

“Á Dança....”

Interação Fisica

"O Olhar..."

Homossexualismo

Feminino

Tendência à tolerância

Doença [desvio e agressẫo]

Doença [agressẫo, desvio e

transgressã̃o]

Doença [desvio e transgressẫo]

Tendências para aspectos

saudáveis

Doença [desvio e transgressẫo]

Tendência agradável

Doença
Discurso, indecisẫo [dificuldade, interdiçẫo, negaçẫo], interdiçẫo [transgressẫo/suspeiçẫo], transgres sẫo

Transgreçẫo, inquisiçẫo, discurso [interdiçẩo], negaçẫo [omissẫo], ironia, medo, dificuldade e empatia

Transgressẫo, discurso, afastamento, interdiçẫo, rejeiçẫo, constrangimento [recriminaçã̃olafastamento]

Discurso [negaçẫo e ironia], suspeiçẫo [ironia], transgressẫo e afastamento

Afastamento [discurso e negaçã̃o], hostilidade, interdiçã̃o, suspeiçẵo $\mathrm{e}$ transgre ssẫo

Constrangimento, transgressẫo, interdição, discurso e afastamento 
Enquanto desvio, a sua manipulação se dá através da interdição e da proibição, pois as identidades sociais e pessoais são parte dos interesses e definições de outras pessoas, em relação ao individuo ${ }^{(9)}$.

Sobre o corpo, a pressão para o mito - a sexualidade como agressão e transgressão

O material do mito é o material da nossa vida, do nosso corpo, do nosso ambiente ${ }^{(10)}$. Dessa forma, a mitologia é viva e ela lida com tudo isso de forma adequada à natureza do conhecimento de cada época.

A mitologia é o meio pelo qual toda e qualquer sociedade reage às questões fundamentais acerca da origem, da vida e do destino de cada um de nós ${ }^{(11)}$.

As bases da compreensão do corpo e da sexualidade do sujeito psicossocial apontam para as manifestações e práticas sexuais, de acordo com as normas societárias. A história de nossa concepção de corpo humano é, portanto, a história dos sistemas de valores realmente fundamentais de cada sociedade ${ }^{(11)}$.

$O$ presente estudo revela alguns sentidos, na medida da sua pressão à intuição, enquanto estrutura de participação mítica ${ }^{(10)}$, e apresentam-se por descrições factuais ${ }^{(11)}$, dentre as quais se destacam:

\section{O mito da onipresença e onipotência. Ocorre na medida} em que a estratégia da observação busca o controle do espaço institucional, e o exercício da autoridade ocorre mediante um discurso polissêmico, conflituoso e ambivalente.

A manutenção do controle institucional sobre a sexualidade do doente mental necessita da participação e conivência geral. Uma rede de observação é estruturada silenciosamente, sem a devida consciência, para que cada um dos elementos envolvidos contribua, exercendo a sua cota, em graus diferenciados, a fim de consolidar as normas e rotinas institucionais.

0 mito da sexualidade como agressão. 0 portador de doença mental é freqüentemente reconhecido como capaz de auto e/ou heteroagressão. Sob o domínio da instituição psiquiátrica, a associação entre sexualidade e agressão está sempre presente.

A valorização do erotismo, reforçada na mitologia do corpo masculino como arma ${ }^{(11)}$, tem por base uma nova concepção de guerra, em que a frustração e a humilhação sofridas pelos homens são metas a serem conquistadas, via estupro. A veiculação dessa guerra interna e sexual tem, na pornografia, sua transformação em mercadoria sexual.

Tal como essas inferências, há uma tendência, no discurso dos enfermeiros, para entender a sexualidade do doente mental como uma agressão, um ato ilegítimo, não aceito pelo profissional.
0 mito da purificação. $O$ corpo do doente mental é objeto de aproximação com o conceito judaico-cristão de pecado, mesmo sem manifestações de sexualidade. Os mitos da criação indicam que somente a procriação justifica a aproximação dos corpos. 0 corpo, entendido como objeto de satisfação sexual, leva ao outro extremo do seu entendimento. Ambas as posições são reducionistas e castradoras.

A sexualidade do doente mental representa um perigo, dada a aproximação do enfermeiro como o "lócus da sua práxis", o corpo do outro.

O enfermeiro tenta romper um legado de preconceitos e estigmas sobre sua conduta, estruturada socialmente ao longo da história. O longo tempo de permanência nas instituições, a proximidade dos corpos das pessoas que nelas trabalham e a relação dominação-submissão nas relações profissionais despertam fantasias que o enfermeiro enfrenta, durante o exercício profissional.

0 enfermeiro procura vencer essas barreiras e, com isso, estabelecer novo patamar para sua identidade social. A concretude do seu dia-a-dia o faz confrontar-se com a realidade que vem se confirmando na prática, uma tendência e uma pressão à reordenação gradativa do espaço de atuação no contexto institucional.

Concluindo, a sexualidade do doente mental é reconhecida e negada pelo enfermeiro, nas pranchas deste estudo. Afasta-se do foco, enquanto posicionamento terapêutico, circunscrevendo-o a uma área de perigo, no enquadre das transgressões.

Adota o discurso como o elemento mediador e revelador desse distanciamento, conferindo um certo grau de envolvimento, por se tratar de ato legítimo da autoridade que se revela na forma de poder, frente à "ilegitimidade" da conduta do doente mental.

A percepção da sexualidade do doente mental, expressa pelos enfermeiros, apresenta aspectos ambivalentes, contraditórios, complexos e polissêmicos, constituindo o seu espaço ideativo e interativo, enquanto discurso.

\section{CONCLUSÕES}

As novas práticas da enfermagem e as transformações de suas representações sociais são reconhecidas como o clássico, de execução das prescrições médicas, o próprio, caracterizado por uma definição de funções próprias, com autonomia (...), e, uma prática nova, bastante recente, que vem se impondo de forma progressiva ${ }^{(12)}$.

Ancorado na estratégia de um movimento defensivo, o enfermeiro apresenta, no material coletado, a ênfase relacional entre contexto e objeto, cujo discurso revela a sua inabilidade com a temática, a dificuldade para atuar nesse campo, por desconhecer a sua legitimidade. Revela também a ambigüidade, enquanto conflito 
desencadeado pela sua exposição diante da cena e o que se espera dele enquanto profissional.

A maneira como é encarada a questão determina o seu envolvimento e direciona sua atuação. Revela um posicionamento $\mathrm{e}$ um comportamento situados na sua atitude discursiva. Estabelece um vínculo com a ideologia dominante do contexto institucional.

O profissional evidencia, independentemente da instituição a que pertence, sua negação da sexualidade do doente mental. 0 enfermeiro, percebendo a dramática cena apresentada nesta pesquisa, procurou situar-se, utilizando-se de três movimentos diferenciados e interligados:

Inicialmente, o enfermeiro percebe a temática enquanto sexualidade; emite um juízo de valor ante o impacto e/ou surpresa, constatado pelo seu primeiro olhar sobre a situação. 0 julgamento empreendido define a orientação e a atuação nessa situação, ou seja, esta é percebida e assimilada como algo agradável e/ou desagradável.

Em seguida, nega a sexualidade do doente mental. Elabora um discurso que tenta equilibrar os conteúdos contidos nas instâncias do pensar e do falar. Prioriza a verbalização, atribui qualidades que reforçam a sua intenção de negar a sexualidade do doente mental, transportando-o para a esfera da ilegitimidade que o fato confere, por ser um conteúdo latente, face aos desdobramentos históricos e sociais, cuja influência é marcadamente presente na prática atual. Essa ilegitimidade, atribuída à sexualidade do doente mental, o enfermeiro procura enquadrar nas cenas, como doença, agressão, desvio ou transgressão. Incipientemente diluída na mensagem totalitária das representações clássicas da enfermagem, observa-se leve tendência para reconhecer a sexualidade como um sinal de saúde.

\section{REFERÊNCIAS BIBLIOGRÁFICAS}

1. Winnicott DW. Objetos e fenômenos transicionais. Rio de Janeiro (RJ): Francisco Alves; 1978.

2. Vaisberg TMJA. O uso de procedimentos projetivos nas pesquisas de representações sociais: projeção e transicionalidade. Rev Psicol 1995; 6(2):103-7.

3. Anzieu D. Os métodos projetivos. Rio de Janeiro (RJ): Campos; 1984.

4. Miranda FAN. Doente mental: a sexualidade negada. [Dissertação]. Ribeirão Preto (SP): Escola de Enfermagem/USP; 1997.

5. Perrusi A. Imagens da loucura: representação social da doença mental na psiquiatria. São Paulo (SP): Cortez; 1995.
Finalmente, ao perceber que este é um foco da sua intervenção, o profissional tende a efetuar uma classificação e seleção, avaliando, de forma autônoma, a conduta do doente mental.

Entretanto, prevalecem as elaborações simbólicas clássicas sobre o fato, revelando o conflito situado nessas instâncias. Manifestase por meio de um discurso impessoal. Atua e demonstra 0 reconhecimento desse espaço de intervenção, posicionando-se por meio de meios e recursos que qualificam esse foco, atribuindo uma significação, compreendida como adjetivação da negação, sendo realçada pelos atos de indecisão, interdição, transgressão, negação, suspeição, dificuldade, medo, afastamento, hostilidade, ironia e recriminação.

Emite um posicionamento estruturado no seu discurso, revelando sua percepção e compreensão sobre o corpo. Ao situá-lo espacialmente, adota o entendimento de que esse corpo é fragmentado, resultante da doença mental e da sexualidade. Adotando essa atitude, o enfermeiro estabelece vínculos com a ideologia dominante do contexto institucional.

A negação da sexualidade do doente mental assenta-se sobre uma base mítica, elaborada e compartilhada socialmente, reproduzida no contexto institucional.

0 modelo de atuação do enfermeiro, na visão tecnicista, estabelece os meios de atendimento do portador de doença mental, de forma a cumprir as determinações do poder hegemônico, com raras intervenções no sentido de uma assistência compreensiva ou, ainda, com enfoque humanista.

No âmbito geral desta análise, há indicações de que 0 profissional enfermeiro tem consciência da realidade paradigmática que norteia a sua prática. Entretanto, o modelo ideal de paradigma é uma conquista a ser empreendida por cada um de nós.

6. Moscovici SA. A Representação social da psicanálise. Rio de Janeiro (RJ): Zahar; 1978.

7. Maingueneau D. Novas tendências em análise do discurso. Campinas(SP): Pontes; 1993.

8. Schilder P. A imagem do corpo: as energias da psique. São Paulo (SP): Martins Fontes; 1980.

9. Goffman E. Estigma: notas sobre a manipulação da identidade deteriorada. Rio de Janeiro (RJ): Guanabara; 1988.

10. Campbell J. As transformações do mito através do tempo. São Paulo (SP): Cultrix; 1990.

11. Highwater J. Mito e sexualidade. São Paulo (SP): Saraiva; 1992. 12. Guimelli $C$, Jacobi D. Pratiques nouvelles et transformatión dês representations sociales. Rev Internat de Psychol Sociale 1990; 3(3):307-34. 